\title{
Human Frontiers Program to go international in Switzerland
}

\section{Tokyo}

AfTER years of deliberation, Japan's Human Frontier Science Program will finally begin today ( 28 July) with the launch of a pilot grant programme. More important, the Science and Technology Agency (STA) and the Ministry of International Trade and Industry (MITI) are shortly to propose that the full-scale programme be launched next year, backed by an international foundation to be established in Switzerland.

The move to establish a foreign scientific foundation designed to support international basic research is without precedent in Japan. Cooperation will be sought from scientists of the 'summit' nations (Japan, United States, United Kingdom, Canada, France, West Germany, Italy and the European Community).

Tateo Arimoto, director of planning in the STA's Science and Technology Policy Bureau, says the foundation and programme will be modelled "flexibly" along the lines of the European Molecular Biology Organisation. The foundation will be

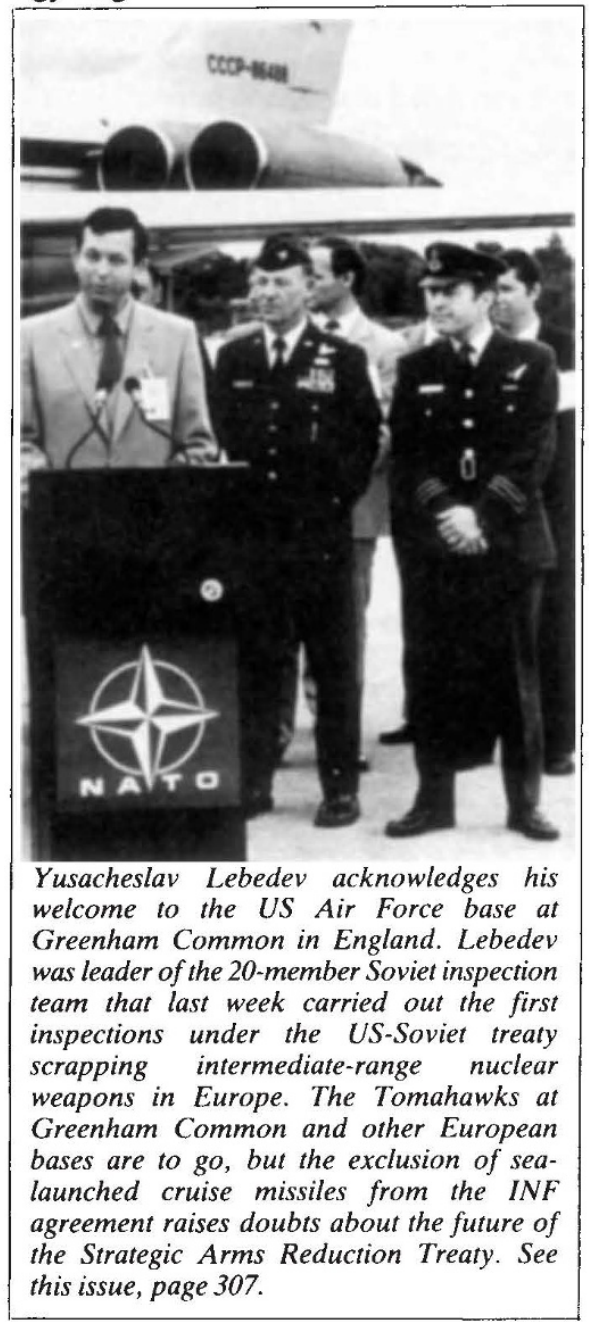

entirely funded by Japan in the initial phase; STA and MITI will request "a minimum of $\$ 20$ million" to start things going in fiscal year 1989. The first international grants should be available from the Swiss foundation in about October 1989.

Although other summit nations will not contribute funds in the initial stage, Arimoto says that the US National Science Foundation and the European Community will provide experienced personnel for the administrative secretariat of the programme. And scientists from all summit nations will participate in the governing council and peer review committees of Frontiers. Ultimately, Arimoto hopes to reach a multilateral agreement for the establishment of an organization similar to the World Health Organization and funded by all summit nations.

A committee of 20-25 summit scientists will convene the first of several meetings this autumn to discuss the way Frontiers will begin. And four or five international workshops on the brain, the human genome project, molecular recognition and non-invasive techniques for scanning biological functions will be held in the period up until the end of fiscal year 1988 (March 1989); the agency has set aside $¥ 300$ million ( $\$ 2.25$ million) for them in this fiscal year.

Meanwhile, MITI today announced the availability of international grants under an 'experimental' Frontiers programme (see the 'Classified' section, page 22). Five grants worth up to $¥ 30$ million ( $\$ 225,000$ ) will be awarded in this fiscal year to "international joint research teams" composed of researchers from institutions in at least three summit nations, one of which must be Japan (this latter condition may be dropped in the full-scale programme).

Grants for research into 'high-order brain functions' or 'molecular recognition and response', will be for up to two and a half years and will be administered by the New Development Organization (NEDO).

NEDO is a a semigovernmental organization that was set up jointly by MITI and private industry in 1980 to build pilot plants for tapping alternative energy sources. But under legislation passed last spring, the organization will be re-organized to incorporate many of MITI's major research and development programmes, including Frontiers (see Nature 333, 4; 1988). Other Japanese ministries may join Frontiers from fiscal year 1990.

The Ministry of Education, Science and Culture (Monbusho) was apparently shocked when MITI was awarded $¥ 170$ million (\$1.3 million) for distribution of the international grants this year. Although the amount of money involved is relatively small, basic research and international collaboration in science has traditionally been the preserve of the education ministry.

According to a Monbusho adviser, the ministry has "reluctantly" entered into negotiations with the STA and MITI and is still maintaining a 'wait-and-see' attitude. But STA and MITI officials are now confident that they they have the full backing of Prime Minister Noboru Takeshita and will win the funding they want.
David Swinbanks

\section{Creeping towards reform in Australian higher education}

Sydney

Australia's higher education system is being reformed a little at a time. In a 'pay for productivity' deal, academic researchers have agreed to allow the number of untenured senior academic posts to increase from 3 per cent to around 10 per cent of total posts.

Also part of the package is the adoption of uniform provisions for the dismissal of academics on grounds of unsatisfactory performance, and an early retirement scheme. Until now, serious misconduct has been the only basis for firing an academic. The early retirement scheme should see 1,000 academics retire over the next three years.

These moves are all among reforms designed to increase the flexibility of higher education institutions that was advocated in a green paper by the Minister for Education, Employment and Train- ing, Mr John Dawkins (see Nature 330 592;1987).

Academics will receive a 4 per cent pay rise that will cost the government an extra A $\$ 46$ million in the next year. No extra money will be forthcoming in succeeding years, since by then the 'productivity gain' is expected to have worked its way through the system. Further changes to academic's rights may come from a log of claims submitted to arbitrators by university vice chancellors. One contentious request is that some academics may be released on grounds of redundancy.

Although academic unions maintain their commitment to tenure, Professor Ralph Hall, vice president of the Federation of Australian University Staff Associations, says that if the vice chancellors can win the power to make academics redundant, "tenure will become virtually meaningless."

Charles Morgan 